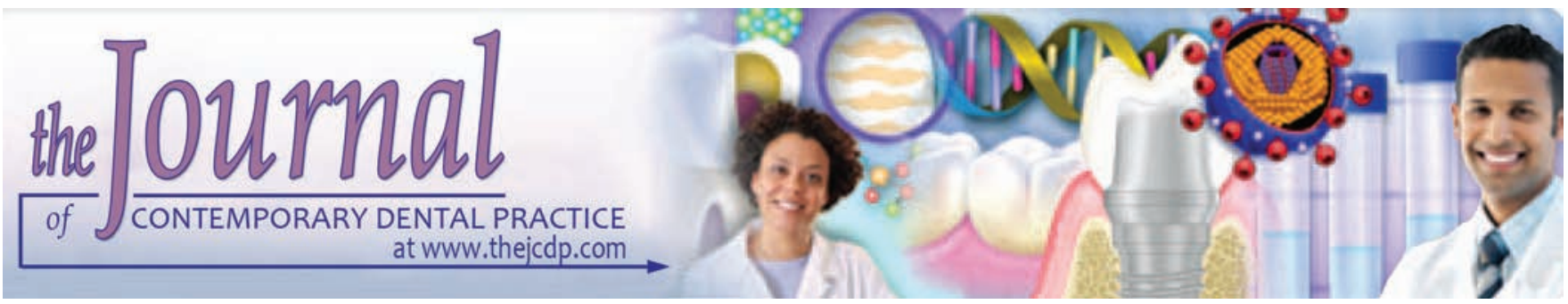

\title{
Comparison of Platform Switched and Sloping Shoulder Implants on Stress Reduction in various Bone Densities: Finite Element Analysis
}

Joji Markose, ${ }^{2} \mathrm{~S}$ Suresh, ${ }^{3}$ Shruthi Eshwar, ${ }^{4} \mathrm{~K}$ Rekha, ${ }^{5}$ Vipin Jain, ${ }^{6}$ Supriya Manvi

\begin{abstract}
Introduction: Comparison of platform switched (PS), sloping shoulder, and regular implants on stress reduction in various bone densities with finite element analysis.

Materials and methods: A total of 12 three-dimensional finite element models were built to analyze the stress distribution model. Nobel Biocare $4.3 \times 8 \mathrm{~mm}$ regular platform replace select implant with matching diameter easy abutment, Nobel Biocare $4.3 \times 8 \mathrm{~mm}$ replace select implant PS with $3.5 \mathrm{~mm}$ diameter easy abutment, Bicon $4 \times 8 \mathrm{~mm}$ implant with $4 \mathrm{~mm}$ diameter sloping shoulder abutments were created virtually in compact bone density using software. The $130 \mathrm{~N}$ axial force and a $90 \mathrm{~N}$ oblique loading force were applied to the abutment to analyze the stress.
\end{abstract}

Results: Under horizontal and vertical loading, the sloping shoulder implant had lesser stresses in cancellous bone when compared with PS and regular implants. Sloping shoulder implant showed more stress distribution at implant-abutment interface and at crestal area, whereas with regular implants, the stresses were distributed at cortical area.

Conclusion: Sloping shoulder implant in subcrestal position is much favorable for bone growth, stress distribution, and preservation of remaining bone.

\footnotetext{
${ }^{1}$ Cosmo French Medical Center, Sharjah, UAE; Department of Prosthodontics (Implantology), Cosmo French Medical Centre Sharjah, United Arab Emirates

2Department of Prosthodontics, and Crown and Bridge, The Oxford Dental College \& Hospital, Bengaluru, Karnataka, India

${ }^{3-5}$ Department of Public Health Dentistry, KLE Society's Institute of Dental Sciences, Bengaluru, Karnataka, India

${ }^{6}$ Department of Prosthodontics, KLE Society's Institute of Dental Sciences, Bengaluru, Karnataka India

Corresponding Author: Shruthi Eshwar, Department of Public Health Dentistry, KLE Society's Institute of Dental Sciences Bengaluru, Karnataka, India, Phone: +9184969920111, e-mail: shruthy2015@gmail.com
}

Clinical significance: Use of sloping shoulder implant design distributes the stress apically and creates lesser stresses when compared with PS implants.

Keywords: FEM, Platform switched, Sloping shoulder, Various bone densities.

How to cite this article: Markose J, Suresh S, Eshwar S, Rekha K, Jain V, Manvi S. Comparison of Platform Switched and Sloping Shoulder Implants on Stress Reduction in various Bone Densities: Finite ElementAnalysis. J Contemp Dent Pract 2017;18(6):510-515.

Source of support: Nil

Conflict of interest: None

\section{INTRODUCTION}

The goal of prosthetic dentistry is to develop an ideal substitute for the partial or completely missing teeth. A dental implant is a surgical component that interfaces with the jawbone or skull bone to support dental prosthesis. ${ }^{1}$ The success or failure of a dental implant depends on a variety of factors including patient health, amount of stress on the bone, and design of the abutment. Implant failure often occurs because of insufficient/lack of biomechanical bonding between the implant and the supporting jawbone, improper implant tooth fixtures, or abutment failure. ${ }^{2}$

Platform switching refers to the use of prosthetic abutments that have a smaller diameter than the implant. In general, vertical bone loss of 1.5 to $2 \mathrm{~mm}$ and horizontal bone loss of $1.4 \mathrm{~mm}$ occurs after abutment placement. It may be due to the lack of hermetic sealing of the junction between the implant platform and abutment, which results in a microgap where the bacteria can grow. Usage of platform switched (PS) implants leads to central shifting of the inflammatory cell infiltrate and away from the crestal bone. This helps preserve the bone around the implant in all three dimensions and the gingiva, while 
also contributing to esthetic advantage. Further, the PS implants provide more flexibility for implant placement. ${ }^{3}$

Sloping shoulder concept refers to transfer of occlusal loads to the bone when positioned below the bony crest and provides room for the bone over the implant, which provides support for the interdental papilla enabling esthetic gingival contours to be easily and consistently achieved. $^{4}$

The finite element method (FEM) refers to a numerical technique for structural analysis, which involves dividing a structure into simpler parts called finite elements. These finite elements are collectively known as mesh when assembled at the corner nodes. When the nodes are subjected to certain load, it results in change in the mechanical behavior of the model, which is similar to structure of representation. The accuracy of results are influenced by the type, arrangement, and the total number of elements. ${ }^{5}$

The biomechanical performance of implant designs and the impact of clinical factors on the success of implants can be predicted with finite element analysis (FEA). An understanding of the basic principle, application, methods, and limitations of this concept in implant dentistry can help the clinician to interpret the results of FEA studies better and extrapolate the results to clinical scenarios. The FEAs have been used to study the effects of various shapes of dental implants on distribution of stresses generated in the jawbone and also establish an optimal thread shape that can ensure better distribution of stress. ${ }^{6}$

The occlusal force at the bone implant interface is a principal factor that determines the outcome of the implant. Hence, the implant design must ensure distribution of the functional forces to the supporting structures within the physiological values. Further, the implant design between the implant head and the abutment can affect the biomechanical behavior of the implant. ${ }^{7}$

It is difficult to simulate living bone tissues and their response to mechanical forces applied while modeling the mechanical behavior of dental implants. ${ }^{8}$ Design philosophy, diameter, length, and the shape of implants as along with the biomechanical bond between the jawbone and implant have been widely evaluated. Most of this research has concentrated on the biocompatibility of the implant materials with an aim to reduce the potential risks, which could lead to clinical failure. However, ideal implant design still remains to be understood while there is also a lacunae related to the understanding of the biological interaction that takes place at the implant-living tissue interface. ${ }^{9}$

The use of FEM enables the clinician to gain an indepth knowledge about the stress encountered by the implant as well as the jawbone. The implant design and the insertion techniques can be optimized based on this information. Hence, understanding the principles, applications, and the limitations of these technologies is vital for the clinician to interpret the findings of such evaluations and apply the outcomes to clinical situations. ${ }^{9}$

Hence, this study was conducted with an aim to compare the influence of PS and sloping shoulder implants on stress reduction in various bone densities.

\section{MATERIALS AND METHODS}

This was a descriptive comparative study where 12 three-dimensional (3D) finite element models were built to analyze stress distributions. Each model comprised an abutment, abutment screw, implant, and bone. The stress was analyzed by applying an axial force of $130 \mathrm{~N}$ and an oblique loading force of $90 \mathrm{~N}$ to the abutment.

\section{Implant Systems}

- Nobel Biocare $4.3 \times 8 \mathrm{~mm}$ regular platform replace select implant with matching diameter easy abutment

- Nobel Biocare $4.3 \times 8 \mathrm{~mm}$ replace select implant PS with $3.5 \mathrm{~mm}$ diameter easy abutment

- Bicon $4 \times 8 \mathrm{~mm}$ implant with $4 \mathrm{~mm}$ diameter sloping shoulder abutments.

These 3D finite element models were virtually created in compact bone density using software.

\section{Material Properties}

The physical properties of the components modeled for this study are elaborated in Table 1 . The implant, abutment, and the abutment screw were of titanium alloy with an elastic modulus of $105 \mathrm{GPa}$. The bone density modeled was of compact bone and cancellous bone (with high and low densities) having elastic moduli of 13.7, 1.37, and $0.8 \mathrm{GPa}$ respectively.

\section{Model Design and Interface Conditions}

Each model was exposed to a transverse and axial load of 90 and $130 \mathrm{~N}$ respectively. The abutment heights (from crown margin to the abutment top) of all the models were modified to $5 \mathrm{~mm}$. About $8 \mathrm{~mm}$ of the rough surface of the testing fixtures were completely embedded in the bone, while distance between the crown margin and the crestal bone level was designed to be $1.5 \mathrm{~mm}$.

Table 1: Physical properties of the different components used in the study

\begin{tabular}{lll}
\hline Component & $\begin{array}{l}\text { Elastic modulus } \\
\text { (GPa) }\end{array}$ & $\begin{array}{l}\text { Poisson's } \\
\text { ratio }\end{array}$ \\
\hline Cortical bone & 13.7 & 0.3 \\
Cancellous bone high density & 1.37 & 0.3 \\
Cancellous bone low density & 0.8 & 0.3 \\
Titanium alloy & 105 & 0.3 \\
\hline
\end{tabular}


The 3D section of the mandible was created using a computerized tomographic image of the first molar region of a human edentulous mandible. The width of the human mandible was about $8.5 \mathrm{~mm}$, while its height was about $24 \mathrm{~mm}$ (inferosuperiorly). The 3D finite element models were then designed using 3D model software. Uniform properties were considered for cortical as well as cancellous bone.

\section{Elements and Nodes}

From the three implant systems, 12 finite element models comprising two fixture types in combination with two types of bone quality were formed (Tables 2, 3 and 4). The element size of the refined mesh of the implant, screw, crown restoration, abutment, and cancellous bone was set to $0.4 \mathrm{~mm}$, while that of crestal cortical bone was set to $1 \mathrm{~mm}$.

\section{Finite Element Analyses}

(ANSYS) Analysis System software (version 14.5) was used to perform the FEA and calculate von Mises stress. The 3D model of the sample was formed using computer software and mesh control of the models was also defined using this software. Loads, constraints, and materials were applied after meshing the 3D models. The stress distribution within the implant structure and the supporting bone were analyzed after applying an axial and transverse force of 130 and $90 \mathrm{~N}$ respectively.

\section{RESULTS}

The FEA simulation results established the relation between strain and the loads applied on the implants, its geometrical characteristics, and the joints. The "von Mises" theory is frequently used to determine the stress within the bone matrix, and the same theory was utilized in this study to evaluate the stress distribution at the bone-implant interface.

Table 2: Sloping shoulder (Bicon implants): Elements and nodes

\begin{tabular}{lllll}
\hline & Overall & Cortical & Cancellous & Implant \\
\hline Elements & 355,104 & 113,429 & 92,414 & 21,026 \\
Nodes & 67,674 & 25,587 & 19,814 & 5,256 \\
\hline
\end{tabular}

Table 3: Regular (Nobel Biocare implants): Elements and nodes

\begin{tabular}{lllll}
\hline & Overall & Cortical & Cancellous & Implant \\
\hline Elements & 371,924 & 109,176 & 115,359 & 65,626 \\
Nodes & 70,432 & 24,947 & 24,943 & 14,507 \\
\hline
\end{tabular}

Table 4: The PS (Nobel Biocare implants): Elements and nodes

\begin{tabular}{lllll}
\hline & Overall & Cortical & Cancellous & Implant \\
\hline Elements & 408,790 & 111,160 & 115,359 & 56,578 \\
Nodes & 76,764 & 25,265 & 24,943 & 12,565 \\
\hline
\end{tabular}

Table 5: D2 (Porous cortical \& coarse trabecular) bone results on horizontal loading with different implants

\begin{tabular}{lllll}
\hline & Cancellous & Cortical & Implant & Dispersion \\
\hline $\begin{array}{l}\text { Sloping shoulder } \\
\text { implant }\end{array}$ & 2.908 & 32.636 & 302.433 & 0.0607 \\
$\begin{array}{l}\text { Regular implant } \\
\text { PS implant }\end{array}$ & 7.064 & 44.497 & 105.111 & 0.025672 \\
\hline
\end{tabular}

Under transverse loading of $90 \mathrm{~N}$, the results show lesser stress in the cancellous and cortical bone with Bicon implant arrangement (2.908 and 32.636 respectively; Table 5 and Fig. 1) and higher stresses are observed in the implant and abutment regions (302.433). This indicates larger load sharing of the implant compared with the bone and reduction of stress.

These study results show that when sloping shoulder (Bicon) design is exposed to horizontal loading stress, concentration occurs at implant abutment connection, where the stress is directed toward the crestal area, rather than toward the apical direction, thereby reducing bone resorption, whereas in PS implants, stresses are more concentrated at implant-abutment interface and crestal area. Regular implant stresses are more in cortical areas (Figs 2 and 3).

In general, Young's modulus of the material determines the stress. Since implant and crown are made of materials that have a higher Young's modulus, stress values are more. Cancellous bone has lesser Young's modulus by which stress values are less. On the contrary, cortical bone has almost 10 times higher Young's modulus by which stress is also observed to be 10 times more and also influenced by stress concentration.

Under vertical loading of $130 \mathrm{~N}$, the results show lesser stress in the cancellous and cortical bone with sloping shoulder implant arrangement (1.432 and 9.452
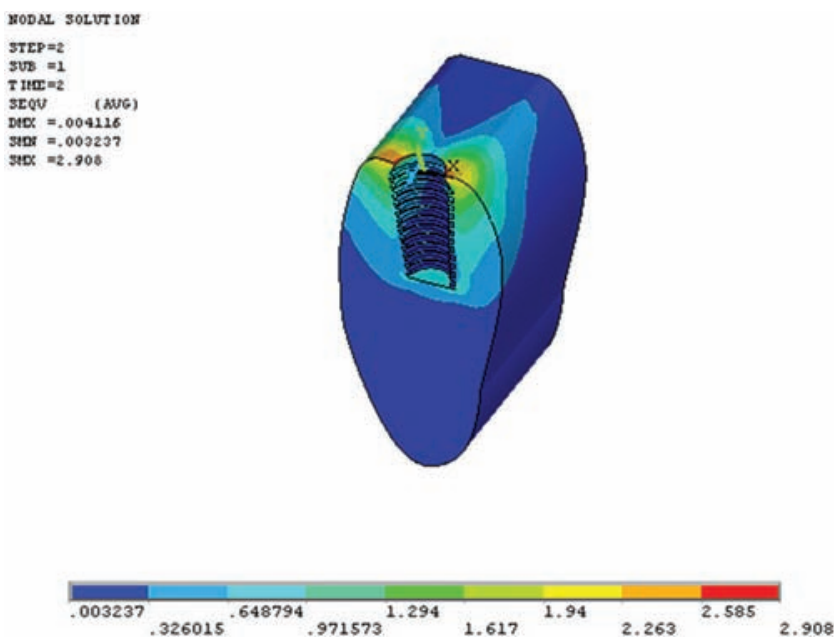

Fig. 1: Sloping shoulder implant design on horizontal load of $90 \mathrm{~N}$ shows more stress distribution at implant-abutment interface, and increased stress toward crestal area 


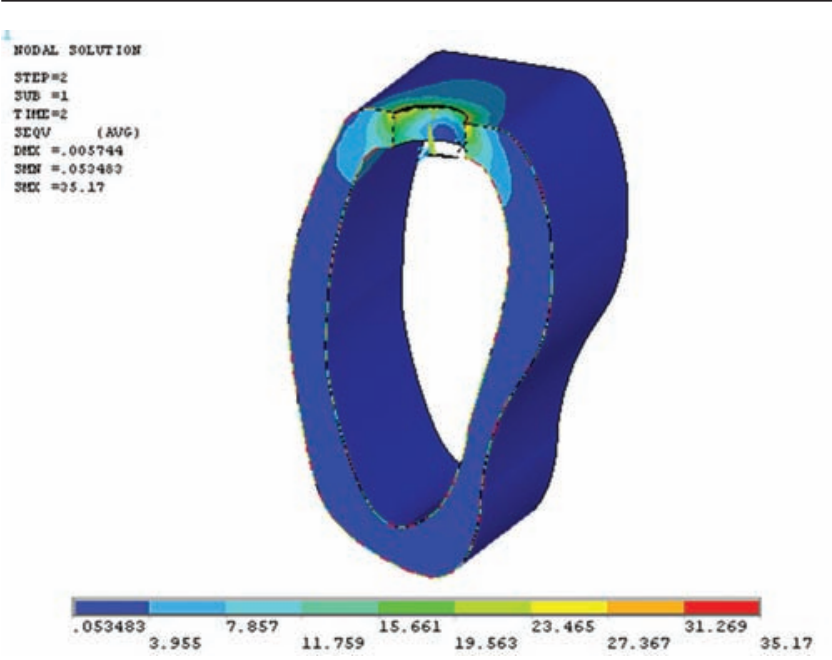

Fig. 2: Regular implant design on horizontal load of $90 \mathrm{~N}$ shows more stress distribution at cortical area

Table 6: D2 (Porous cortical \& coarse trabecular) bone on vertical loading with different implants

\begin{tabular}{lllll}
\hline & Cancellous & Cortical & Implant & Dispersion \\
\hline $\begin{array}{l}\text { Sloping shoulder } \\
\text { implant }\end{array}$ & 1.432 & 9.452 & 36.854 & 0.004159 \\
Regular implant & 1.721 & 11.706 & 20.996 & 0.003 \\
PS implant & 1.606 & 10.381 & 33.64 & 0.003426 \\
\hline
\end{tabular}

respectively; Table 6 and Fig. 4) while higher stresses are observed in the implant and crown regions (36.854 and 34.826 respectively). This indicates larger load sharing of the implant as compared with the bone.

These study results show that under vertical loading, the sloping shoulder (Bicon) implant experiences stress concentration at the apex of the implant. While stress is uniformly distributed toward the lateral directions, higher stress concentration is noted in the apex plateau of the implant thread.

Under horizontal loading of $90 \mathrm{~N}$, the results (Table 7) reveal lesser stress in the alveolar bone with sloping shoulder (Bicon) implant arrangement (25.882) and higher stresses in the implant and crown regions (304.896 and 348.832 respectively). This indicates larger load sharing of the implant compared with the bone, and reduction of stress concentration effects due to shouldering of Bicon implant.

These study results show that under horizontal loading, the sloping shoulder (Bicon) implant experienced lesser stresses in alveolar bone compared with PS and

Table 7: D3 (Porous cortical \& thin fine trabecular) bone on horizontal loading with different implants

\begin{tabular}{llll}
\hline & Alveolar bone & Implant & Dispersion \\
\hline $\begin{array}{l}\text { Sloping shoulder } \\
\text { implant }\end{array}$ & 25.882 & 304.896 & $0.0544(0.03)$ \\
Regular implant & 37.9158 & 107.018 & 0.02 \\
PS implant & 27.43 & 167.724 & 0.024 \\
\hline
\end{tabular}

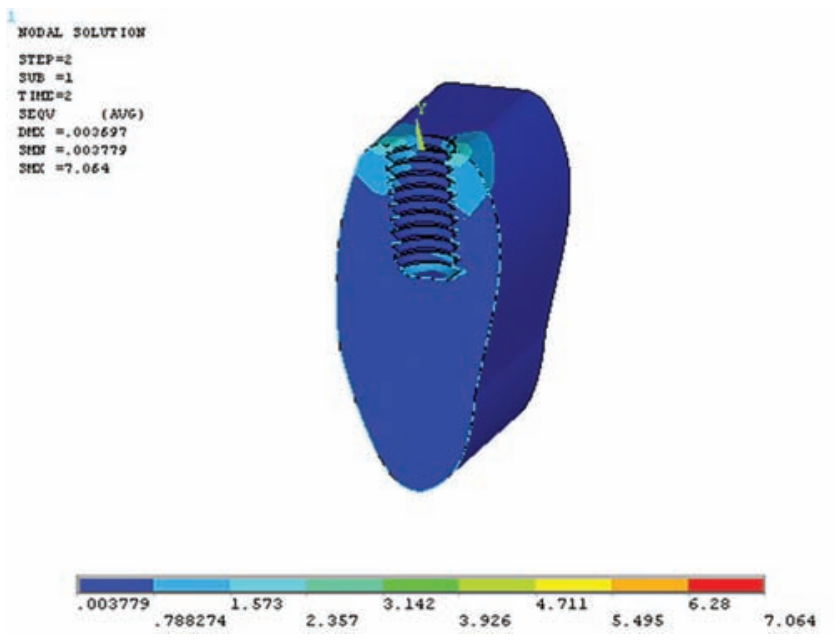

Fig. 3: The PS implant design on horizontal load of $90 \mathrm{~N}$ shows more stress distribution at implant-abutment interface, and increased stress toward crestal area

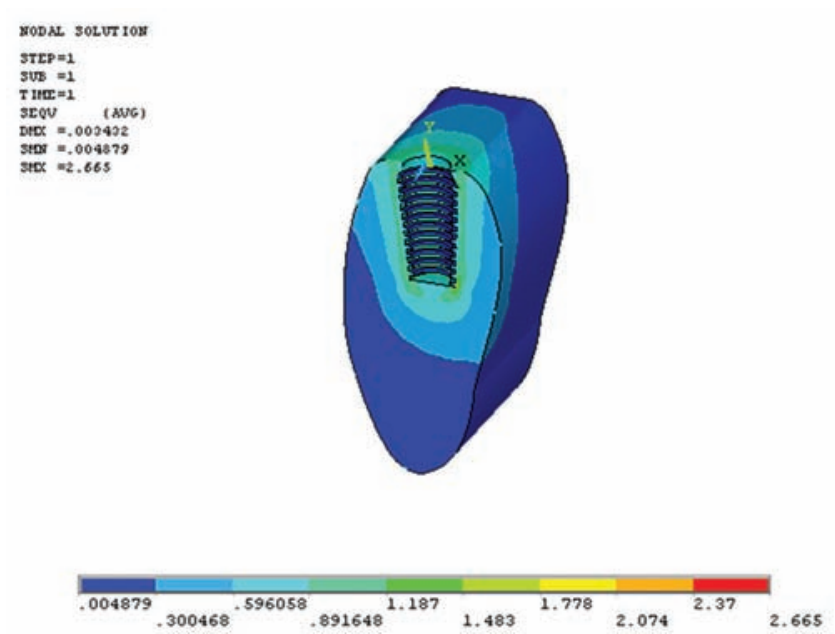

Fig. 4: Sloping shoulder implant design on vertical load of $130 \mathrm{~N}$ shows more stress distribution at apex of the implant and uniform distribution toward lateral directions

regular implants (Nobel Biocare). It was also observed that under horizontal loading, sloping shoulder experienced higher stresses in the implant and the crown areas suggesting stresses being directed more on the implant rather than the bone, thereby reducing bone resorption.

Under vertical loading of $130 \mathrm{~N}$, lesser stress was noted in the alveolar bone with sloping shoulder (Bicon) implant arrangement (4.264; Table 8), while higher stresses were observed in the implant and crown regions (28.6 and 37.1554 respectively). This indicates larger load sharing of the implant compared with the bone, and

Table 8: D3 (Porous cortical \& thin fine trabecular) bone on vertical loading with different implants

\begin{tabular}{llll}
\hline & Alveolar bone & Implant & Dispersion \\
\hline Sloping shoulder implant & 4.264 & 28.6 & 0.001757 \\
Regular implant & 6.06 & 17.127 & 0.001281 \\
PS implant & 4.35 & 19.659 & 0.0013 \\
\hline
\end{tabular}




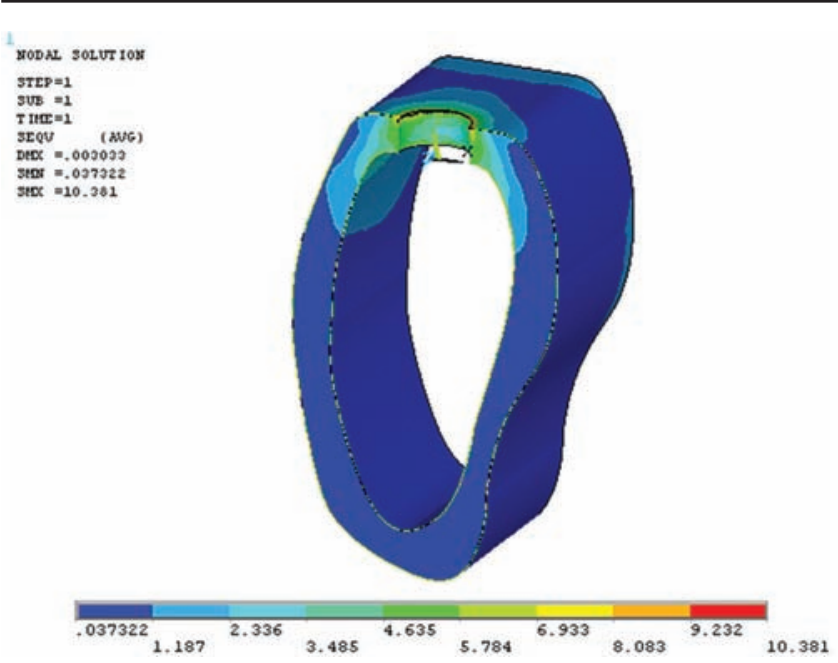

Fig. 5: Regular implant design on vertical load of $130 \mathrm{~N}$ shows more stress distribution at neck of implant

reduction of stress concentration effects due to shouldering of Bicon implant.

Further, under vertical loading, the sloping shoulder (Bicon) implant was associated with lesser stresses in alveolar bone areas compared with PS and regular implants (Nobel Biocare) (Figs 5 and 6). It has also been observed that under vertical loading, sloping shoulder had higher stresses in the implant and the crown areas suggesting stresses being directed more on the implant rather than the bone, thereby, reducing bone resorption.

\section{DISCUSSION}

Immediately after implant loading, the bone resorption is frequently seen near the first thread of the two-piece implants. Hence, the concentration of stresses in the bone should be avoided to maintain stable osseointegration following implant placement. ${ }^{10}$ Reduced crestal bone resorption has been reported with platformswitching technique in a few studies. The bone preservation noted in platform-switching technique has been attributed to inward shifting of the implant abutment junction location or the area of stress concentration between the abutment and implant. ${ }^{11}$

The current study showed that von Mises stress values at the crestal bone were reduced with the sloping shoulder as well as PS implants. Crestal bone resorption is reported to occur following disproportionate load and damage of the supporting interfacial bone. ${ }^{12}$ Inappropriate stress concentration around the implant may cause microfracture of the supporting bone and crater-like bone defects, eventually leading to bone loss around the implant. Platform-switching concept reduces the von Mises stress in the peri-implant bone tissue and the implant, according to Tabata et al. ${ }^{13}$ A reduction in the abutment diameter decreases the amount of stress

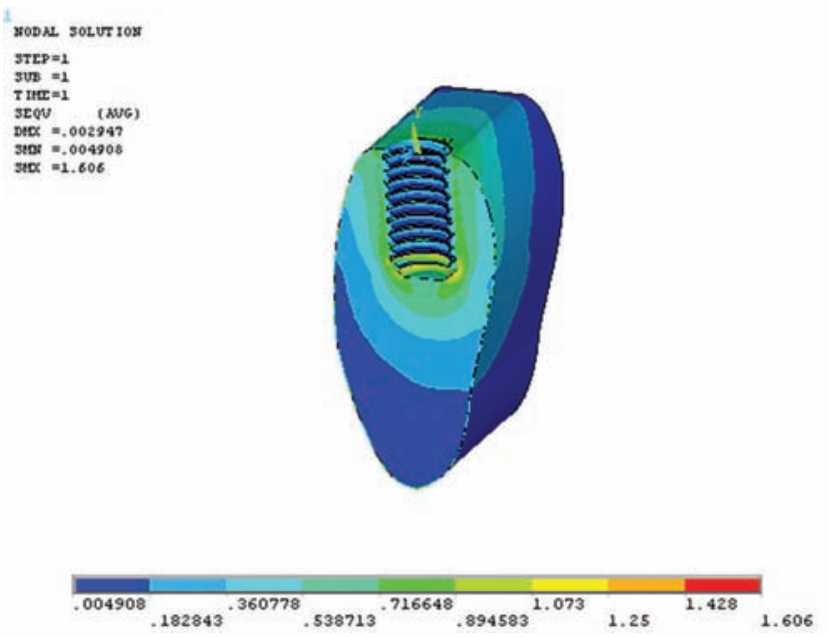

Fig. 6: The PS implant design on vertical load of $130 \mathrm{~N}$ shows more stress concentrated at apex of implant, where the stress is distributed toward the crestal area

transferred to the crestal bone, according to FEA by Hsu et al and Schrotenboer et al. ${ }^{14,15}$

It should be noted that the outcomes of our study contradict that reported by Pessoa et al. ${ }^{16}$ This may be attributed to the difference in the definition of platform switching. In the study by Pessoa et al, circumferential horizontal mismatch of $0.5 \mathrm{~mm}$ between implant and abutment was defined as platform switching, while in our study, the horizontal mismatch was $1 \mathrm{~mm}$. Platformswitching concept is considered to impact mechanical properties of the implant-abutment complex rather than the stresses (load induced) developed at the marginal bone around implants. ${ }^{17}$

The current study results suggested that stress value was lesser while the stress distribution was more favorable with sloping shoulder and PS implant designs compared to regular implants. Contact between the implant and the bone can be enhanced by increasing the implant diameter, thereby, resulting in a dramatic reduction in the stress concentration.

Further, the horizontal and vertical stresses at the compact bone around the implant neck were noted to be lower in sloping shoulder and PS models compared with conventional models. Excessive compressive stress can compromise the periosteal blood supply leading to bone necrosis and may eventually increase bone resorption risks. Bone loss can also occur following exposure to high tensile stress. Therefore, it can be said that the risk of bone resorption and osseointegration loss can be minimized with PS design of both systems. In a similar study, compressive and tensile stresses at the crestal bone around implants were noted to be higher in the conventional model compared with platform-switching model. ${ }^{18}$

As reported in other studies, the current study suggests that stress concentration at the implant-abutment interface 
increases with the platform switching. Such an increase in stress at the implant-abutment interface can cause mechanical problems, such as screw loosening or fracture.

The bone-implant contact in the current study was 100\%; however, bone-implant contact percentages in vivo usually range between 30 and $70 \%$. Hence, it can be said that results represent an average clinical situation, and the generalization of study results should be carried out with caution. Further, it is difficult to replicate all clinical situations with finite element models, and hence the outcomes of the study must be applied based on sound clinical judgment.

\section{CONCLUSION}

The minimum stress in the trabecular bone in sloping shoulder implants is lesser than that in the PS implants or regular implant design. It is also suggested that the sloping shoulder implants are biomechanically suitable for cortical bone as well as cancellous bone since the stress distribution pattern is more favorable for the biological bone growth than bone loss. This study also indicates that the inclusion of an oblique load and wearing of the cortical bone quality are important parameters used to simulate the biomechanical characteristics of the dental implant system. This study also confirms that compared with vertical and horizontal loads, sloping shoulder implant in subcrestal position is much favorable for bone growth, stress distribution, and preservation of remaining bone.

This work is of significance not only in adopting the advanced model reconstruction in FEA to obtain reliable data to lend powerful reference and guidance to clinical application, but also in design and optimization of the new type of implant, which can extremely reduce the stress peak of cortical layer.

\section{REFERENCES}

1. Kalanović M, Zdravković-Petrović N, Milošević M, Nikolić D, Zdravković N, Filipović N, Kojić M. Three-dimensional finite element analysis of SKY implant system. J Serbian Soc Comput Mech 2010;4:87-96.

2. Eskitascioglu G, Usumez A, Sevimay M, Soykan E, Unsal E. The influence of occlusal loading location on stresses transferred to implant-supported prostheses and supporting bone: a three-dimensional finite element study. J Prosthet Dent 2004 Feb;91(2):144-150.

3. Sahabi M, Adibrad M, Mirhashemi FS, Habibzadeh S. Biomechanical effects of platform switching in two different implant systems: a three dimensional finite element analysis. J Dent (Tehran) 2013 May;10(4):338-350.
4. Nisand D, Picard N, Rocchietta I. Short implants compared to implants in vertically augmented bone: a systematic review. Clin Oral Implants Res 2015 Sep;26(Suppl 11):170-179.

5. Przemieniecki JS. Theory of matrix structural analysis. J Sound Vib 1969;10:358-360.

6. Danza M, Palmieri A, Farinella F, Brunelli G, Carinci F, Girardi A, Spinelli G. Three dimensional finite element analysis to detect stress distribution in spiral implants and surrounding bone. Dent Res J (Isfahan) 2009 Fall;6(2):59-64.

7. Lee JH, Frias V, Lee KW, Wright RF. Effect of implant size and shape on implant success rates: a literature review. J Prosthet Dent 2005 Oct;94(4):377-381.

8. Gultekin, BA.; Gultekin, P.; Yalcin, S. (2012) Application of finite element analysis in implant dentistry, In: Ebrahimi, F., editor, Finite element analysis - new trends and developments. InTech; 2012. Available from: http:/ / www.intechopen.com/ books / finite-element-analysis-new-trends-and-developments/ application-of-finite-element-analysis-in-implant-dentistry.

9. Ergatoudis J, Irons BM, Zienkiewicz OC. Curved, isoparametric, quadrilateral elements for finite element analysis. Int J Solids Struct 1968 Jan;4(1):31-42.

10. Cardaropoli G, Lekholm U, Wennström JL. Tissue alterations at implant-supported single-tooth replacements: a 1-year prospective clinical study. Clin Oral Implants Res 2006 Apr;17(2):165-171.

11. Lazzara RJ, Porter SS. Platform switching: a new concept in implant dentistry for controlling postrestorative crestal bone levels. Int J Periodontics Restorative Dent 2006 Feb;26(1):9-17.

12. Brunski JB. In vivo bone response to biomechanical loading at the bone/dental-implant interface. Adv Dent Res 1999 Jun;13:99-119.

13. Tabata LF, Rocha EP, Barão VA, Assunção WG. Platform switching: biomechanical evaluation using three-dimensional finite element analysis. Int J Oral Maxillofac Implants 2011 May-Jun;26(3):482-491.

14. Hsu JT, Fuh LJ, Lin DJ, Shen YW, Huang HL. Bone strain and interfacial sliding analyses of platform switching and implant diameter on an immediately loaded implant: experimental and three-dimensional finite element analyses. J Periodontol 2009 Jul;80(7):1125-1132.

15. Schrotenboer J, Tsao YP, Kinariwala V, Wang HL. Effect of platform switching on implant crest bone stress: a finite element analysis. Implant Dent. 2009;18:260-269.

16 Pessoa RS, Vaz LG, Marcantonio E Jr, Vander Sloten J, Duyck J, Jaecques SV. Biomechanical evaluation of platform switching in different implant protocols: computed tomography-based three-dimensional finite element analysis. Int J Oral Maxillofac Implants. 2010; 25:911-919.

17. Canay S, Akça K. Biomechanical aspects of bone-level diameter shifting at implant-abutment interface. Implant Dent 2009 Jun;18(3):239-248.

18. Chang PK, Chen YC, Huang CC, Lu WH, Chen YC, Tsai HH. Distribution of micromotion in implants and alveolar bone with different thread profiles in immediate loading: a finite element study. Int J Oral Maxillofac Implants 2012 Nov-Dec;27(6): e96-e101. 